\title{
A Pulse Before Shelf Life: Literary Advice on Notebook-Writing as Event
}

\author{
Arne Vanraes
}

What if the book with all its wiles and daring were only mad resistance against the emptiness of the last page? (Jabès 1991, p. 205).

It belongs to the goodness of the world, that its settled order should deal tenderly with the faint discordant light of the dawn of another age (Whitehead 1978, p. 339).

\section{INTRODUCTION}

The notebook is a tool entangled with the roots of creative writing pedagogy and is a time-honored component in the culture of literary advice that intends to guide the aspirant author in coming-to-writing. Already in one of the earliest examples of western writing advice, "The Art of Fiction" discussion between Sir Walter Besant and Henry James (1884), Besant encouraged the method of consistent note-keeping and claimed that "(t)he learner must carry his note-book always with him"

\footnotetext{
A. Vanraes $(\bowtie)$

University of Leuven, Leuven, Belgium
}

(C) The Author(s) 2021

A. Masschelein and D. de Geest (eds.), Writing Manuals

for the Masses, New Directions in Book History,

https://doi.org/10.1007/978-3-030-53614-5_10 
(Besant and James 1884, p. 21 ). With his stress on systematically implementing the notebook as the student's attribute, he expressed his concern for wanting to jump to the polished literary product prematurely. The "elements of Art" (ibid., pp. 21-22) are acquired in the experiential encounters with one's environment and in the preliminary practice and study of composing these experiences into the text. Yet, Besant is equally adamant in his later book of instruction, The Pen and the Book [1899], that "the desire alone" is not enough, and that the student must write "Something"-and with mastery (Besant 2012, pp. 5, 49). Thus, we are confronted early on with the issue that, for all its radically open-ended qualities, the notebook as such can seem at odds with a pedagogical project of formulating specific and practical advice on the inflection point where writing tout court determines some order for the attainment of an end and may be offered up for evaluation. While agreeing with Besant's insistence on taking notes, Henry James is explicit at his turn in the debate when he remarks the lack of precision regarding what goes into the notebook: "But this I fear (the novelist) can never learn in any hand-book; it is the business of his life" (Besant and James 1884, p. 67).

How curious, then, that a century after these early examples of western writing advice, this is precisely what began to surface: instructive documents and handbooks specifically dedicated to keeping a notebook or writer's journal. Virtually all the classics of twentieth-century literary advice consistently place great value on the practice (e.g., Dorothea Brande, Brenda Ueland, Natalie Goldberg, Julia Cameron, Peter Elbow), but since the mid-1990s examples started to emerge among NorthAmerican publications where the notebook takes center stage. In this essay, I will discuss two more conventional handbooks, Ralph Fletcher's Breathing In, Breathing Out. Keeping a Writer's Notebook (1996) ${ }^{1}$ and Aimee Buckner's Notebook Know-How. Strategies for the Writer's Notebook (2005), and three compilations of writers' testimonies on their own praxes of note-taking which carry an instructional intent, The Writer's Notebook, edited by Howard Junker (1995), The Writer's Journal. 40 Contemporary Authors and Their Journals, edited by Sheila Bender (1997), and Writers and their Notebooks, edited by Diana Raab (2010).

My focus is their process-pedagogical approach to the notebook and how it functions as a lure for linking up the ingredient elements of the event of writing into some concrete unity-the problematic determinacy of writing "something" Besant and James already addressed. How could 
one conceive of a writing ahead of its occurrence? How to anticipate writing's definition before the singularity that distinguishes the event of its coming-to-be? And what with the imperative of finishing, when every instant of writing's satisfaction becomes a condition for the event to advance beyond this determination?

\section{END-Less Writing: Writing's Event}

Henry James's early critical remark about the notebook's indefinable contents already intimates the absence of any single imitable template that would dictate pedagogical formulas. Anything goes. Records of observations and copies of things read, impressions remembered and traps set against oblivion, lists for coherence and musings to gain understanding, the urgent notice of a sudden revelation or a fleeting dream, secrets saved from the public eye, stock taken for the work of art underway, and so on. Additionally, the variety of authors writing reflective pieces on their note-taking praxes compiled by Howard Junker, Sheila Bender, and Diana Raab illustrates the wide range of textual modes and poietic forms that may emerge from them: novels, poetry, short stories, memoirs, criticism, etc. Howard Junker maintains: "Anything can be tried because nothing is at stake. No one is watching: there is no script, as there is in a rehearsal, to obey" (Junker 1995 , p. 2). ${ }^{2}$ One finds that notebooks as a whole share few elements between them that could conveniently be generically coded or standardized by literary institutions. They cannot easily be made intelligible or be evaluated by how closely they resemble a group of other texts that adhere as a genre. Therefore, whenever the guidebooks approach note-taking-in-itself and initially set out to explain what it is, they perform a different function from the genre-normative one that has been observed in literary advice on, for instance, the American short story (Levy 1993), the popular romance novel (De Geest and Goris 2010), or mystery fiction (Masschelein and de Geest 2017). Early on, the issue presents itself of how we can address Creative Writing's foundational question: "Can it be taught?" when there seems to be no it to teach?

In search of some unifying determinant among notebooks, we might consider the private diary, to which they are positioned in ambiguous proximity. Due to their common instrumentality and the open-endedness of the notebook, the advice books will sometimes cover both forms interchangeably when discussing the "writer's journal." Yet there are many advice authors, too, who note vital differences between them. One 
common claim for their distinctions is that the notebook, unlike the diary, is somehow more than the factual accounting of the day's proceedings (a point also made in Joan Didion's well-known essay On Keeping a Notebook [1968] and Michael Taussig's extraordinary notebook study $I$ Swear I Saw This [2011]). It lends itself to the surplus of "inner life" and "sensory detail" (Denise Levertov in Bender 1997, p. 185), the deeper "emotional landscape" of experience (Fletcher 1996, p. 47), the crisisdriven "journey" beyond the day's matter-of-factness (Maureen Stanton in Raab 2010, p. 72), and it has a broader scope than diarists' "fascination with their own lives" (Robin Hemley in Bender 1997, p. 121 and in Raab 2010, pp. 17-18). Moreover, Aimee Buckner argues that the diary is an "end" in itself (Buckner 2005, p. 35), which contrasts with Marianna de Marco Torgovnick's claim of the notebook as a space for "working" (in Bender 1997 , p. 295). In short, the notebook is too committed to supplemental processes and transitional potentialities to easily be considered an end in itself.

Howard Junker's terminology is telling when he calls notebooks a niche among "preliterary" or "subliterary genres" (Junker 1995, p. 2) in the context of creative writing, which neighbors the blanket concept of "prewriting" frequently used in writing pedagogy to cover note-taking. Such terms are suggestive of how strongly preconceptions about creative writing are implied in the prospect of the work of art and expectations of writerly ambition tied to publication and profession. The writer's notebook as a typically private, unpublished and transformational processdocument can elude these associations. It embodies perhaps what Graeme Harper names the "acts and actions" of creative writing, as opposed to the cultural and commercial "commodity value" of finished works (Harper 2010). The creative work exists, as well, in the lot of its preand post-working - spadework, most of which is rarely published-and in the participation of gestures that are always already more than the completed work to begin with. Hence, Harper imagines a more liberal use of the "creative writer" label that is radical and simple: "To continue to be a creative writer someone must be writing, creatively," and holds that "Creative Writing doesn't begin at the point at which a creative writer ceases to do it" (ibid., pp. 8, 27; original emphasis). An irony of the literary advice industry is that it carves out a segment from the consumer market where it commodifies the acts and actions of creative writing. The operations formative of the creative artifact begin to supplement it as a 
commodity and few kinds of writing enable this better than the so-called preliterary genre of note-taking.

So, if the notebook is not an end in itself, then is it a means to an end, if we take that to signify a pure implement of design? Not quite. The notebook advice typically does not predefine an eventual formative outcome, for example in the form of a composed and codified work aimed at public consumption. Instead, it takes on an intensely process-pedagogical approach and joins in its freewriting methodologies. When Diana Raab states in an appendix to her compilation that "There are as many ways to journal and use journal entries as there are ways to write" (in Raab 2010, p. 191), she is essentially implying that the principle ordering element that may be abstracted from the writer's notebook is writing as such. The intention proclaimed by the notebook-guidebooks is then very often to get students writing at all. Ralph Fletcher is emphatic: "The point of a writer's notebook is nothing more nor less than writing-first person and intimate, sincere or experimental — on a regular basis" (Fletcher 1996, p. 94). Likewise, Aimee Buckner maintains that "the most important aspect of a notebook is that it allows students the practice of simply writing $[\ldots]$ in whatever form. Writing, writing, writing" (Buckner 2005, p. 7), and Dorianne Laux promotes: "Journaling. All the time. Write, write, write" (in Raab 2010, p. 149). While there are still signals to be found that the composition of a work for publication is likely the writer's eventual desire, this "glory of glories," as Katherine Towler calls it (in ibid., p. 36), is purposely postponed and the "use value" of the student's notebook is not instantly measured against it. Instead, an act of writing is encouraged whose creative expanse outreaches its imagined fulfillment. Robin Hemley observes: "this is often when I write my best work, when I'm not trying too hard to make $A r t$ " (in ibid., p. 18; original emphasis). Similarly, Gary Snyder advocates "no special literary pretension, and no obligation to "make use" of any of it" (in Junker 1995, p. 203), and for Elizabeth Woodly, the notebook "is a release from deeper obligations, of attempts to write in a "higher language" (in Bender 1997, p. 326).

In other words, in their suggestions for how students should first approach their notebooks, these guidebooks invite a kind of end-less writing: a creative activity that survives both its predefinition and its termination. It endures as it differentiates and is differentiated by any temporary attainment of purpose and thus baffles the imperative to finish. This end-less writing is relevant to that which Roland Barthes called writing as an "intransitive verb" or writing "in the absolute sense," whose 
"tending-toward" matters more than its direct object, its "something" (Barthes 2011, pp. 14, 141, 144-148). Given the firm associations of creative writing with generic codes and the myth of the finished, public Work, this interpretation of a "writing for writing's sake" could easily be caricatured as writing no-thing-at-all, which risks reducing the notebook to a hollow index, turning note-taking purely gestural and making the writerly position no more than postural. As an analog technology that is shared in intimately physical social environments, the notebook permits such enactment comfortably, as Omar S. Castañeda illustrates: "It seems such a sign of a writer that it is the most efficient way for those nonwriters in coffee shops to keep alive their highly visible pretense of ambition" (in Bender 1997, p. 42).

End-less writing, however, is of course not devoid of objects altogether, but indulges rather in the abundance and impermanence of writing's potential inclinations, its uncertain tending-toward and pointing-beyond. This is part of the reason why the notebook inspires a legitimately egalitarian view on the activity of writing and why it is so attractive to the dilettante. It helps remind us that even those celebrated authors who did end up composing their writing into some satisfied unity, decided to offer it up for publication and eventually gained acclaim with it, have witnessed their own end-less initiations, often in their own unspectacular notebooks. Howard Junker articulates it effectively: "To writers, at every career stage, our notebooks offer, I think, a kind of ultimate, reverse inspiration: 'Look how ordinary, how lost and styleless - and how courageous - a great writer can be. Just like me"' (in Junker 1995, p. 4). ${ }^{3}$ The notebook, by the indeterminacy of its end-less writing, draws "master" and "amateur" into a common field of activity - a potentiality of passage that neither coincides with mock-creativity nor with the guarantee that everyone de facto is a successful professional author in-waiting.

The approach of a kind of "writing for writing's sake" is not a novelty introduced by the notebook-guidebooks alone, but is frequently encountered in the lore of twentieth-century literary advice. Alexandria Peary's study of self-help books for creative writing, for instance, observes in the classics a general "devaluation of publication," by "prolonging the invention phase, assigning more private writing, and allowing students to delay performing for an audience for as long as each individual requires" (see Peary in this book). Precisely this advocacy has served as ground for other scholars, creative writers, and critics to oppose the literary advice culture in the past, as it seems to jeopardize the notion of creative writing as a 
specialized "craft" and undermine the import of the literary profession and its commodities.

In one example, Steve Westbrook dismisses how "we find it perfectly normal to teach students the craft of creative writing by offering them this advice on a regular basis: generate text for the purpose of simply generating text" (Westbrook 2004, p. 143). It is an "illusion of purposeless writing" (ibid.), he claims, that dissuades students from motivating their writing by political engagement and the drive of cultural activism. This ambition of a more reactionary project, combined once more with an implicit evaluation of creative writing by its commodities, however, is arguably an utterly particular preconception of writing's objects and objectives-admirable, perhaps, but contingent nonetheless. The prejudice makes the criticism of the "just do it" mentality within literary advice (ibid., pp. 144-147; emphasis added), somewhat contrived and difficult to extrapolate to the notebook-guidebooks, since their focal point is so often the creative advance of writing's activity beyond any presupposed or objectified actualization. Westbrook does briefly concede that the freewriting advice is perhaps harmless for undergraduates, but I believe John Milne's point about writerly ambition is more succinct when he declares: "Wanting to write and wanting to be a writer are different things. You become a writer because you write, not vice versa" (Milne 2014, p. 404).

Milne's remark, to my mind, pricks the heart of the matter. A part must be reserved for every creative activity where artists do not fully perceive its materials assembled as concrete entities in advance but only witness this coming-together in the movement of a process-already-underway as it culminates in experience. A process can only be surveyed as teleological once it has been satisfied; the end is always already lodged in the past. There is a degree of suspenseful uncertainty where you don't know exactly "what" to write before its being-written has already begun. James Brown believes in a similar sense that "you discover what it is you want to say during the writing process" (in Raab 2010, p. 3), a point echoed more aphoristically by John DuFresne: "Writing engenders more writing" (ibid., p. 113), and Dorianne Laux: "Writing begets writing" (in Junker 1995, p. 169). The uncodified notebook amplifies such a selfpropelling and self-positing kind of creation. It is an instrument of its own becoming; a shared name for both a technology and the impermanent body of instabilities that form its product-in-the-making. 
I would like to take John DuFresne's contention that "The notebook is not an end, but a means" (in Raab 2010, p. 114), to a further extreme and propose with some overemphasis that it can function as a means without an end. The notebook encourages an activity of end-less writing that behaves as a "mediality" or "in-betweenness" which produces objective unity again and again through the incidents of its own middling. This intermediary position between the discrete stabilities of writing something reveals a fault where the criticism of a "just do it" attitude is projected onto writing for writing's sake. It also begs some nuance as to how we have referred to the "acts and actions" of creative writing, accentuated early on in Aimee Buckner's handbook as well: "It's the act of writing the practice of generating text and building fluency - that leads writers to significance" (Buckner 2005, p. 7; original emphasis). You cannot exactly claim to "do it," because this it is never fully established ahead of its occurrence. You could not consider notebook writing as a means to an end within the instability of its coming-to-be, since this or that eventual end is not successfully defined before the actual fulfillment of writing's middling. It cannot be done. An end-less writing, rather than as an act, should really be considered in terms of its event-a happening, self-creative interval which relates and requalifies the materials fed into it and is never entirely in sync with the artist's sovereign intentions or a fact of mere execution. How this interval can yet be fed by the artist, how the event can be induced, will form the topic of the coming discussion.

We asked with Besant and James whether the "it" of notebook writing "can be taught." An awareness that goal-oriented writing refrains with interstices where the materials of writing self-create their togetherness and exceed the writer's expectations entails that the event of writing invents a part of its own pedagogical needs in the process of its happening. The notebook-guidebooks are compelling in their uselessness. It is only obvious to condemn the perceived inconsequentiality of advice such as "don't try too hard to make Art," or "just write for writing's sake," if one already presumes to know beforehand what writing is supposed to amount to, regardless of whether or not that aim is worthy of aspiration. The pedagogical project I gather from the notebook guidebooks is one that, rather than instructing, facilitates the creativity of learning in every project-inthe-making; privileging making sense over accepting common sense. ${ }^{4}$ All writing efforts, regardless of skill and intent, at every stage, spill constantly into and out of self-organizing intervals, pulsing between the writer's 
initiations and experiences, and the materials' tendencies and limitations. One's end is the event's beginning, like a throbbing heartbeat of creation.

\section{Gifted: Creative Receptivity}

The singer-songwriter Townes Van Zandt said of his song Mr. Mudd and $M r$. Gold: "That song came to me in a flash, all at once. It wasn't me that was writing it. It was $[\ldots]$ a giant pencil from the sky" (Van Zandt 2012). Van Zandt was articulating a feeling familiar to many who work creatively. It may appear as if the materials for the inventive process reach us from somewhere beyond our control, happening upon us as in a sort of epiphany that we can only undergo. Another singer-songwriter, Daniel Johnston, stated that the titular promise of his song True Love Will Find You in the End comes with a catch: "Only if you're looking can it find you." In the amorous as in the writing event, we are visited by affective forces that overwhelm the spirit. But Johnston adds an irony to the passivity suggested in Van Zandt's example: such accidental interventions can actively be invited.

This paradox of an active passivity is in line with a kind of on-demand creativity frequently promoted by the notebook-guidebooks. Time and again, their points of advice are derived from the same core notion of a self-inflicted inspiration where the writer's authority must first be relinquished and affirmed in its fugitive dispersion. Then, the unanticipated elements amplified by that escape can reconvene to inspire new initiations that begin as more calculated inductions, whose backwash is again propelled by the next involuntary inflow. This is a dialogical version of two historically juxtaposed interpretations of creativity that in western literary advice date back at least to one of its earliest instances, Edgar Allan Poe's The Philosophy of Composition (1846). Many publications within the culture have since continued to uphold this duplicity. On one side is found "the Muse": creation ignited by rapturous impulse, organic intuition, ecstatic frenzy, which occur as spontaneous visitations. On the other side is located the ideology of "craft": writing as a matter of methodical skill, honed technique, design, discipline, step-by-step composition. Other texts, like the notebook-guidebooks, however, propose a spectral continuum that folds in aspects of its extremes toward a re-enchantment of the thoroughly professionalized and institutionalized pursuit of creative writing: a compromise of creative receptivity, active passivity, attentive inattention, willed involuntariness, a 
consciousness of the unconscious. The discourse of these documents is revealing. Synonyms for the creative process found in the cases of this essay include stumbling, following, getting seized, being struck/grabbed by, reawakening, capturing, summoning, fueling, sparking, haunting, dazzling, hatching, jump-starting, nudging, and launching. The materials of creation are imagined as triggers, catalysts, gifts, rumblings, seeds, sparks, or springboards.

Appropriate to the belief that creativity's generative components cannot entirely be planned of one's will, the notebook advice rejects the pretension that all aspects of writing could be learned by following technical poietic recipes-something must be left to chance encounters and discoveries not hypothesized. Ralph Fletcher announces in the introduction to his notebook-guidebook: "You won't find any clever formulas or neat recipes in these pages" (Fletcher 1996, p. 5), and Diana Raab prefaces her compilation by proclaiming: "There is no formula for keeping a notebook" (Raab 2010, p. ix). Instead, we are told that "Your notebook can help you live in a state of creative readiness: to be sensitive to ideas and inspiration the way a piece of photographic paper is sensitive" (Fletcher 1996, p. 16), and that "A writing journal is only a process by which one looks at life" (Raab 2010, p. 125). Put differently, the pedagogy of creative receptivity deals not necessarily in precise writing techniques. It tries rather to impart certain attitudes, orientations, or dispositions toward the seduction of inspiring influences active in the peripheries of one's awareness. Students are conditioned into a particular positionality that encourages a relation of mutual qualification with those highly mobile materials that so easily migrate beyond that which can be anticipated. For David Mas Masumoto, the important thing is to "capture the creative spirit" (in Bender 1997, p. 207), and, as Mark Pawlak learned from his teacher Denise Levertov, the notebook offers such "a way of inviting the Muse" (in Raab 2010, p. 135).

Despite their re-enchantment of creative writing, the invocation of the Muses appears in the notebook-guidebooks in a demystified form. Ralph Fletcher, for instance, prefers "a more plebeian vision of the process" to that of the Muse (Fletcher 1996, p. 14). Inspiration will not necessarily manifest as gems of profound insight tailored to the literary registers that desire them, but tends to hide out in the mundane environments of dayto-day life. "The Muse is as likely to sit across the bar from you as to come by your office for a chat," writes John DuFresne. (in Raab 2010, p. 119). Those are the kind of maneuverable spaces where the student 
can adopt certain attitudes to attract that which might "serendipitously" become relevant to artistic work, and requires real effort rather than being a congenital capacity. In this respect, the notebook, once more, takes up an intermediary position. As the common instrument of both quotidian observations and creative writing, it straddles two universes which Fletcher names "a real life and a textual life" (Fletcher 1996, p. 30), and which Diana Raab identifies as "one's personal life and literary life" (Raab 2010, p. 185). The notebook is a waystation that directs and gives temporary refuge to literature's embryonic particles as they are in transit between universes. The advice thus goes: take your notebook out into the world and subject yourself to those impulses that are so hard to come by from the isolation of the writer's room, i.e., literary life alone.

This idea of mundane inspiration underlines again that literary art is not conceived within the vacuum of a system of writing conventions whose rules one must simply internalize. Rather, as in Walter Besant and Henry James's early claims, the elements of art are the business of one's life. The event takes nourishment as "Our pen drinks deep at the veins of the moment," to phrase it with the writer Edmond Jabès (Jabès 1991, p. 156). The materials for writing are afforded by the world; the appetite of literary becoming grows in that world's "literary" lived experience. And herein lies a major significance of the notebook's instrument. The technological co-extensiveness of notebook, body, and environment yields a highly particular way of experiencing the drawing-out of elements for artistic work and their transduction ${ }^{5}$ into written form. Robin Hemley testifies: "I find that when I carry my journal, things worthy of being recorded seem to pop up all around me, which leads me to suspect, of course, that these things are always happening around me. I'm just more observant when I have my journal with me" (in Bender 1997, p. 18).

As the notebook qualifies the dispositions of its carrier, a text that has still to invent itself is already attracting materials for the incident of its formal taking. Roland Barthes cited Gustave Flaubert's belief in this orientation: "I am a man-pen, I feel through the pen; because of it, in relation to it and so much more with it" (Barthes 2011, p. 147). Reginald Gibbons, as well, articulates it beautifully when he calls keeping a notebook a "being-in-language" (in Bender 1997, p. 79). If writing inspiration is a matter of mutual solidarity between the affordances of everyday habitats and the creative-receptive attitudes of their inhabitants, then note-taking becomes something like a way of thinking and feeling more than a practice ancillary to experience; a way of living, whose event 
is satisfied by occasions of the word coming into its own. This notion is reflected by Katherine Dunn, when she argues: "These notes exist because thinking about a project doesn't all take place during specified, official writing time. You grab ideas when they come, and they come oddly, triggered by anything, because the novel is always in the back of your head" (in Junker 1995, p. 85). When living permanently in the mobile studio of the notebook, "writing time is all the time" (Buckner 2005, p. 94). ${ }^{6}$

If writing time is all the time, since lures for literary tending hide out in the quotidian environment, there is a fault in wanting to separate "private" note-taking and "literary" writing absolutely. And if the creative event involves reciprocal conditioning between writer and writing, they cannot be divorced as producer and product. In a staunch defense of creative writing as a matter of craft and skill, Nancy Kuhl puts forward such an essentialist dyad of, on the one hand, literary and public writing, and, on the other hand, a totally homogenized mass of journal writing, diary writing, personal, private, self-expressive, egocentric, and therapeutic writing. Kuhl is convinced that "Private journal and diary writing [...] differs dramatically from literary writing. [...] Generally, private writing is an end in itself" (Kuhl 2005, p. 4). I am not. In addition to the habitual assimilation of literature with the business of its public commodities, the equation of private writing and egocentric, even therapeutic, writing is problematic (and potentially dangerous). I see no reason why personal writing in the writer's journal should of necessity be born from egomania. In the creative-receptive orientation, where the environment's literary affordances entice and are tempted by the subject's "being-inlanguage," the components of this subject's constitution are added as only "one" among several agencies that partake in the creative event as it culminates in that subject's experience.

The writerly subject is not the be-all and end-all of writing. Its dynamic archive joins the generative elements and formative potential of a larger relational activity of disjunction advancing into conjunction-an argument for humility, much more than for egocentricity. This is a way to interpret the sense of creative depersonalization in Townes Van Zandt's example, namely as a being-with the other ingredient agencies of the event on the cusp of climaxing self-creatively into an occasion of writing. To give just one example, Kuhl's own repeated mention of the sitcom Sex "in" the City demonstrates how the materials of language co-compose with the writer and produce creative accidents. A “journal writing" that is end-less and creatively receptive to more impulses than one could 
sovereignly intend cannot be equated with mere self-expression or even self-discovery, because "the" self, with each event, is in the making; its being is itself the articulation of an effect. Once more with Barthes: "To Write, middle verb: I write, and in doing so I'm affected in the very process of writing" (Barthes 2011, p. 148; original emphasis).

"Dramatically" setting apart literary writing from private writing, which includes the mundane observations in the notebook, avoids the shared materials and potential nomadism between the contextual and textual universes too comfortably. We find an alternative point of view early on in Ralph Fletcher's notebook-guidebook: "If I want to write movingly I must first pay attention to what moves me" (Fletcher 1996, p. 11). He at once intimates the passageways between the personal and the literary, as well as the joint creativity of the self and the influences in excess of it, its more-than. Literary is neither any writing that is conventional or published, nor just anything that is merely noted down, but rather a writing within which a force of feeling is kept astir. Fletcher's adage brings to mind how Gilles Deleuze and Félix Guattari understand art and literature as the preservation of affects (e.g., Deleuze and Guattari 1994, pp. 163-199). To the writer, actively stepping into new environments, notebook in hand, is a kind of sensation provocation. From these occasions of encounter between body-notebook-world, felt intensities emerge, and the writer tries to preserve a "liveness" of feeling for their repetition by mobilizing just the right language forms. These forms and their constellations become the building blocks for the labor of composition-vocabulary, syntax, rhythm, etc.-so that the writer in a sense composes with forces of feeling, which may originate in the most quotidian encounters. The meaning of such preservation is not identical endurance, but creative resonance: singularities of experience are escorted to the verge of new immediacies, as when the memory of a past occasion is enlivened by an affect that is both the particular residue of that past and its "real-time" vibrancy. Lisa Shea, in a discourse of her own, outlines a strikingly similar process:

In journaling, raw emotion is extruded into words onto the page, which are then lifted and transformed through the imaginative process of creation, then reexperienced, tasted again, but from a distance, in a way that is pleasurable. This transformation-the release, return to, and reshaping of pure-bodied emotions I spill into my journal; this attempt to make 
meaning; to make art from raw experience- traces the journey from despair to ecstasy. (in Raab 2010, p. 76)

The refrain of creative receptivity, of being moved and writing movingly, is the foundation for much of the notebook advice. Immediacies of feeling get fed into and spill out of writing's event. In. And out. Intensities migrate from milieu to milieu and survive by adaptation; a dynamic that could be imagined as a pulse, even though its causality and trajectory are not always apparent. For the writer, the notebook may serve as the vehicle for these travels between "real" or "personal" and "textual" or "literary" universes. It explains why Reginald Gibbons, for example, finds "live words with feeling and thought still pulsing in them" in his notebooks (in Bender 1997, p. 77; in Raab 2010, p. 123), and why Roland Barthes considered note-taking a form par excellence to produce the "concision of affect and writing" (Barthes 2011, p. 107).

To my mind, then, it makes sense to interpret certain points of advice in the notebook-guidebooks from the perspective of creative receptivity and the mediation of immediacy. I list here the most frequently recurring ones, some of which overlap with the lore of literary advice as a whole, but are interesting in light of this particular philosophy. Declutter your mind and observe-relinquish preoccupations so as not to drown out the other agencies of the creative event. Take your notebook everywhere-live in a state of creative readiness where the world's literary becoming is disposed through a being-in-language. Write down everything, all the time and record observations and conversations from everyday environments-anticipate and tend to the potential of travel between contextual and textual universes. Give importance to detail, write small - the intensity of feeling may peter out if it is smothered by verbosity or premature conformity to convention. Record dreams, extreme emotions and indelible memories, and do so without censorship-pay attention to the immediacy of those unsolicited experiences that are not predestined by the writing project's design. Read a lot, take reading notes and collect quotes-collect language forms as resources to transduce and preserve forces of feeling. Reread your notes and practice reliving - find examples in your own notations where writing's form succeeded at preserving the singular experience of past occasions into new immediacies. 


\section{Besideness: Making a Difference}

Despite the notebook-guidebooks' promoting of a writing for writing's sake, they do recognize the common want for active publication. At some point students might wish to "take control" of their scribblings and envision those aspects of generic codes and textual modes with which their note-taking was not necessarily concerned before. The reality is that few writers achieve authorship through the production of notes alone, and some students might desire bringing their own toward a more conclusive piece of writing that could perhaps even be made into a literary commodity-the habitual association of published and finished writing is never entirely unsettled in the guidebooks. After all, notebooks are not only seducers of inspiration and records to take-note of incidents as they happen. They are also workbooks; appliances for the word's becoming to be sculpted further and pass on into other texts. "Notebooks are, by definition, workbooks, deliberately kept as part of a transformative process" (Howard Junker in Junker 1995, p. 2). They are seminal documents; they carry seeds in which their potential future budding is immanent and, what is unique, they formalize this refrain of concrete unity and its uprooting in the instants of writing's rebeginning.

This transitional dynamic of notes passing on into new textual order involves a certain excess value, a besideness. What did not ensure relevance in the event's phasing into one synchronized stage of the literary work's development might still come to modulate the next phase of concrescence. What's beside "the point" matters (maybe). A text, a notebook's textualizing leap, is not confronted head-on, but rather obliquely, from the side, curving along with all kinds of vectors in and expansions of the notebook's materials and the writer's evolving subjective particles. Even at the stage where the text takes on a more pronounced form as writing's object, and trajectories are etched and habits born from the recurrence of the same data within successive events, there will always remain the eventful novelty of that which exceeds that text (even after the fact of publication, as many writers will know to their despair). We witness the emergence of another type of creative figure: the re-writer. I take besideness here as a name for rewriting's participation in the morethan or other-than of a text's particular actualization, the surplus of its togetherness.

Kathleen Tyau wonders: "Why do we think published writers including our favorite writers - got the words right the first time around?" 
(in Bender 1997, p. 300). Yet Michelene Wandor, in a criticism of what she considers the patronizing tone of literary advice books, doubts that similar perceived assumptions live up to reality, asking "did anyone ever really think that a novel/poem/play appeared complete and perfectly formed in its final published version?" (Wandor 2008, p. 114). Perhaps not. But, ironically, the repeated derision of critics toward the common "writing for writing's sake" ideology within literary advice, as well as the curriculum's required filiations, certainly drive the debutant's vulnerabilities into a similar paranoia. One could wonder who, actually, holds these beliefs; and whose tone, in fact, is really patronizing. These inquiries may well coincide with the question of who presumes to be in-the-know and whose know-how pushes to curb the eventness of writing creatively from its incipience.

Alexandria Peary, for instance, refers to the " "get-your-thinking-rightfirst-then-write' approach of much writing instruction in the 1960s" (see Peary in this book). Aimee Buckner, whose notebook-guidebook is aimed at creative writing teachers working with nine-/ten-year-old students, makes a great point about "the afraid-to-be-wrong syndrome," where children learn from a very young age that "if they do the task correctly the first time they won't have to do it over" (Buckner 2005, pp. 95, 23). Educators often reinforce such a "guess what's already in my head" attitude all the way into higher education. This particular brand of pedagogy can dramatically impede creative work, discouraging it from (re)inventing its pedagogical needs in and upon the process of its materials coming together. After the advice of an end-less writing for writing's sake and that of the creative-receptive orientation, a third major group of advice that I find in the notebook-guidebooks consists of strategies and the conditioning of attitudes around doing things over; the besideness of textual becoming in rewriting.

The title of Ralph Fletcher's notebook-guidebook, Breathing In, Breathing Out, imagines the preserving of feeling in word forms in the notebook as inhaling, and the work of rewriting those materials into a text as the exhaling phase of the pulse before shelf life. In. Out. Flowing. Ebbing. "Breathing Out suggests that the notebook is a fine place from which to take what you have collected and use it to spark your own original writing" (Fletcher 1996, p. 2). The notebook-guidebooks hold rereading and reworking to be just as crucial as the initial transductions between world and word in note-taking. A major recurring couple of 
recommendations in this respect urges students to examine their notebooks for inchoate ideas and consider the importance of bad writing. Ralph Fletcher proposes that, in their notebooks, students should keep alive what he names, after Carl Rogers, unprepossessing "infant ideas" (ibid., pp. 1-5). They are those early stirrings of thought that are assumed quickly because their chaotic entanglement of forces seems somehow significant, even though the relevance among and beyond the factors of this knot is only discriminated as trivial or vague. However, when these infant ideas are kept alive, which we could understand as affect preservation, they have a tendency to weave their value together with other materials and let writing's event develop further after the antecedent fact of notation: "my writing down these few words was not really my first attempt to begin to create a scene for the larger work, but rather a kind of marker buoy that I threw into the waters to remind me to go back and search the depths beneath it," we read in Reginald Gibbons (in Raab 2010, p. 121).

The notation of infant ideas, in other words, nestles a kind of writing out of time, already implied in the futurity of its rekindling, never fatally self-synchronized. Kim Stafford describes her notebook beautifully as "the location for my own first handshake with the infinite" (in ibid., p. 23). Rebecca McClanahan refers to the notebook as a "compost heap" (in ibid., p. 127), while Ralph Fletcher imagines it as an incubator: "It gives you a place to incubate very new ideas before they are strong and mature enough to face the harsh light of rational judgment, let alone public scrutiny" (Fletcher 1996, pp. 1-2). Upon rereading the notebook, the quiver of embryonic ideas encounters and alters the Work's developing conception and their common relevance is narrowed down. They begin to function for the re-writer as what Aimee Buckner terms "seed ideas" (Buckner 2005, p. 29) that motivate the continuation of writing. If we should again resist this advice for how it predicates us as utterly clueless, consider how often we forego caring for (or even just noting down) a moving idea just for its faint shimmer of intensity, the bare reason of its infinite feeling. How often we get discouraged when it does not instantly serve the imagination of a larger structure like a text or work of literature, or when our internalized audiences already disapprove. Wendy Call reflects on her own practice that: "unadulterated is the perfect word to describe journal writing. The sentences in my journal are those laid down fresh, unencumbered, and undamaged by the internal and external 
censors that buzz around our words as we polish them for public display" (in Raab 2010, p. 88).

Rather few of our infant ideas and the initial transductions between environment and language in the notebook are readily adapted for integration into a common, coherent framework. They tend to arrive ugly, clumsy, poorly symbolized. As I argued with Robin Hemley they come end-lessly when we are not trying too hard to make Art. Yet, despite their disorderly welter among the many pages of the notebook archive, they carry the potential for successive intervals of form-taking. One proposed way to cultivate the originative aptitude suspended in notes is to seriously entertain unpolished, bad writing. Phillip Lopate contends in his preface to Diana Raab's compilation that: "No one can expect to write well who would not first take the risk of writing badly. The writer's notebook is a safe place for such experiments to be undertaken" (in ibid., p. viii). In the process-document of the notebook, bad writing is an exercise in impermanence, more than an end result of ineptitude. Its chaos informs propositional openings for the ingredient elements of notes to spiral inward into new nodes. Ralph Fletcher attests how: "It is not that I try to write badly in my notebook. But I know I will be doing exactly that, just like countless other writers before me" (Fletcher 1996, p. 56).

Based on this awareness, the notebook-guidebooks generally approach failure in attaining the artwork affirmatively, as something to recover rather than recover from. "We need to allow ourselves to fail," Fletcher states (ibid.). This implies by no means that our ambitions should be limited to bad writing. Instead, it supports how notes that are poorly integrable into one junction of the text-at-ease can still serve as an offering of resources to yet another event that survives this impermanent formation as it baffles its order. Surprise is the hope of writing's endurance. The continuation of writing is an adventure of the textual object's morethan, lifted from its besideness by the act of rewriting, before this excess perishes in its turn as the experience of another concrete form. Thus, failure is creative, for better or for worse, and that which is beside the point makes a difference. It brings along a force of differing. What did not turn out to be relevant to the end of writing can still introduce a creative differential to an event that requalifies how that end previously cohered.

The process philosopher Alfred North Whitehead, whose philosophy I appropriate in this essay, held that "the word Creativity expresses the notion that each event is a process issuing in novelty"; "Creativity is 
the principle of novelty" (Whitehead 1967, p. 236; Whitehead 1978, p. 21). Some "thing" conveniently identified in an apparent state of rest does not therefore infinitely arrest its transitional creativity. Smuggle a little stranger into its ecology experienced as halted and you welcome things happening; things' happenings again take action. Thus the event inevitably bleeds beyond the instant and carries off its matter-of-factness to pass on into novelty. The same is true of the timeless kernels among these notes that continue to tremble with potential despite the fact of their inscription. I believe Kathleen Tyau expresses something of this nature when describing her own practice: "I write about the same thing again and again until I feel something happen, and then I revise, revise, revise. I listen first for the voice and then look for the story, for the real subject. Then I attend to the language, images, and so forth" (in Bender 1997, p. 300; emphasis added).

At the stage of rewriting, the data to be introduced and make a difference can now more explicitly include familiar elements of a more coherent structure, like a text or work of literature. Aimee Buckner's notebookguidebook, for instance, provides exercises to reread and reshape one's notes with a focus on attributes of narrative fiction: genre codes, plot development, character evolution, conflict resolution, paragraph structures, etc. When re-writers eventually dispose their revisions through such elements, the inaugural notes expose their inclinations and shared tendencies toward what genetic criticism calls the "devenir-texte" ("becomingtext"). If this priming were introduced to writing straight away, an abundance of our infant ideas could just spill beyond the mold. Considering the typical prolongation of the invention phase in much of literary advice that I pointed to with Alexandria Peary, it might not come as a surprise that the notebook-guidebooks are most distinctly lacking in providing practical instructions on how to prompt and manipulate this textualization. Even though the chaos of writing's event often does not appear stabilized for very long, rewriting now brings ingredients into the fold that are codified and repeated. There is a missed opportunity in the notebook-guidebooks when they do not formulate more explicitly what those resources can be or how they tend to influence composition. Instead, the transitional potentiality of besideness is once more wrapped up in certain attitudes or mindsets. Most of them are iterations of the following: be patient (wait for it), be gentle and forgiving with yourself, view the notebook as a safe space, and, a classic within the advice culture, writing is serious and hard work. 
I do, however, see an underlying point of interest here. With the besideness in the act of rewriting, concrete elements of textuality are (re)introduced to each other and continue to differentiate feedback loops between what's purposeful and useful and what's end-less and useless. These relays generate surplus values that overwhelm the sum of their parts. This highlights how, even if writing does feel close to functioning as a means to satisfy a predicted end, there is never not an "invention phase" lying in wait. The end procures some resolution, but not sufficiency. It is one of the junctions punctuating writing's event as it stutters and hiccups along into novelty; another nexus knotted into the propositional weave of the nodebook. "Completion is the kiss of death," "The moment is a miniscule door to duration," wrote Edmond Jabès (Jabès 1991, pp. 140, 186). The notebook-guidebooks set apart, firstly, an end-less writing for writing's sake as an event with its own middling ability, and, secondly, the procedure of rewriting where the writer is supposed to take ownership of more purposeful mediations. Yet this should not be taken to suggest an absolute linear seriality issuing in inertia, as if the event's excess would suddenly get drained by the introduction of the writer's intercessions, or the advent of the work would forever kill the creativity of novelty. Rather than terminating one another fatally, the potentialities of these phases exist in one another immanently, in a liaison of reciprocal influence and necessity. With Whitehead: "Each stage carries in itself the promise of its successor, and each succeeding stage carries in itself the antecedent out of which it arose" (Whitehead 1978, p. 165). Writers at any stage of their projects or careers can turn to their notes to find a besideness that untangles and joins anew the temporary togetherness of their texts: "The work is malleable - an evolving, living thing in a constant state of flux" (James Brown in Raab 2010, p. 3).

While the end-less and self-creative event of writing surpasses intentionality and absolute final order with the creative excess of the unknown and thus unsettles the notion of some transcendent architect, it in no way means that creation can do without the writer altogether. To formulate the paradox once more with Whitehead: "No things are 'together' except in experience; and no things are, in any sense of 'are', except as components in experience or as immediacies of process which are occasions in self-creation" (Whitehead 1967, p. 236). The advice in the notebookguidebooks, as I see it, is then not to sit back, relax, and let the Muse do all the work for you. Instead, creative writers are educated to become the event's nurturers, its inductors, trained in escorting the composition of 
materials that qualify its swerve into novelty and encouraged to become acquainted with its quaint inclinations.

\section{Notes}

1. Ralph Fletcher published another notebook-guidebook in 1996, entitled A Writer's Notebook: Unlocking the Writer Within You. I do not cite this work in my essay, since its advice closely parallels his other book, but in a language adapted to readers ages eight to twelve.

2. In order to keep an oversight, when referring to contributions from the compilations edited by Howard Junker, Sheila Bender, and Diana Raab, I cite the compilations in which these texts appear, rather than the individual pieces.

3. This egalitarian view is supported by a peculiar medium of notebook advice which I do not discuss in this essay. Notebooks are available on the market where a blank writing utensil is interspersed with instructional and inspirational writing advice from established authors. The common field of activity between "master" and "dilettante" is thus embodied in a physical object, demonstrating how the notebook is a shared name for both an instrument and its product. An example of this medium is The Signature Notebook Series, published since 2016. Following the same logic, we could refer to the fact that Howard Junker's edited compilation features facsimiles of the contributors' own notes.

4. On the notion of making sense and accepting common sense in pedagogy, in relation to Gilles Deleuze's philosophy, see Snir (2018).

5 . The use of the term "transduction" is borrowed mainly from the work of Gilbert Simondon. Here is a concise definition: "Originating from the sciences and crucially developed in its philosophical implications by Simondon, transduction refers to a dynamic operation by which energy is actualized, moving from one state to the next, in a process that individuates new materialities" (De Assis 2017, p. 696).

6. A particular kind of "being-in-language" is performed by the notebookguidebooks as part of their pedagogical method. One of the reasons why these documents may feel impractical or ineffectual is that their authors are themselves creative writers and they often articulate their advice in creative registers. Yet in doing so, they engage a kind of learning by resonance or osmosis. They orient the dispositions of the learner toward the literary becoming of language, by making it part of the didactic text. Therefore, Michelene Wandor's claim that books of literary advice are "metatexts" (Wandor 2008, p. 108) could be nuanced. Roland Barthes offers an alternative point of view that is relevant to the notebook-guidebooks: "writing 
is not fully writing unless there's a renunciation of metalanguage; Wantingto-Write can only be articulated in the language of Writing: this is the autonymy" (Barthes 2011, p. 9).

\section{REFERENCES}

Barthes, Roland. 2011. The Preparation of the Novel: Lecture Courses and Seminars at the Collège de France, 1978-1979 and 1979-1980, trans. Kate Briggs, and ed. Nathalie Léger. New York and Chichester: Columbia University Press.

Bender, Sheila (ed.). 1997. The Writer's Journal: 40 Contemporary American Writers and Their Journals. New York: Dell Publishing.

Besant, Walter, and Henry James. 1884. The Art of Fiction. https://archive.org/ details/artfiction00jamegoog/page/n28. Accessed 21 October 2019.

Besant, Walter. [1889] 2012. The Pen and the Book. London: Forgotten Books.

Buckner, Aimee E. 2005. Notebook Know-How: Strategies for the Writer's Notebook. Portland, ME: Stenhouse Publishers.

De Assis, Paulo. 2017. Gilbert Simondon's 'Transduction' as Radical Immanence in Performance. Performance Philosophy 3 (3): 695-716. https://www.per formancephilosophy.org/journal/article/view/140. Accessed 21 November 2019.

De Geest, Dirk, and An Goris. 2010. Constrained Writing, Creative Writing: The Case of Handbooks for Writing Romances. Poetics Today 31 (1): 81-106.

Deleuze, Gilles, and Félix Guattari. 1994. What Is Philosophy? trans. Graham Burchell and Hugh Tomlinson. London and New York: Verso.

Fletcher, Ralph. 1996. Breathing In, Breathing Out: Keeping a Writer's Notebook. Portsmouth: Heinemann.

Harper, Graeme. 2010. On Creative Writing. Bristol, Buffalo, and Toronto: Multilingual Matters.

Jabès, Edmond. 1991. From the Book to the Book: An Edmond Jabès Reader, trans. Rosmarie Waldrop. Hanover and London: Wesleyan University Press.

Junker, Howard (ed.). 1995. The Writer's Notebook. San Francisco: HarperCollinsWest.

Kuhl, Nancy. 2005. Personal Therapeutic Writing vs. Literary Writing. In Power and Identity in the Creative Writing Classroom, ed. Anna Leahy, 3-12. Clevedon, Buffalo, and Toronto: Multilingual Matters.

Levy, Andrew. 1993. The Culture and Commerce of the American Short Story. Cambridge: Cambridge University Press.

Masschelein, Anneleen, and Dirk de Geest. 2017. So You Think You Can Write... Handbooks for Mystery Fiction. In Crime Fiction as World Literature, ed. Louise Nilsson, David Damrosch, and Theo D'haen, 91-108. New York and London: Bloomsbury. 
Milne, John. 2014. How to Be a Writer. The Handbook of Creative Writing, ed. Steven Earnshaw, 401-406. Edinburgh: Edinburgh University Press.

Poe, Edgar Allan. 1846. The Philosophy of Composition. http://xroads.virginia. edu/ HYPER/poe/composition.html. Accessed 22 November 2019.

Raab, Diana M. (ed.). 2010. Writers and Their Notebooks. Columbia: University of South Carolina Press.

Snir, Itay. 2018. Making Sense in Education: Deleuze on Thinking Against Common Sense. Educational Philosophy and Theory 50 (3): 299-311.

Van Zandt, Townes. 2012. Townes Van Zandt Mr. Mudd and Mr. Gold. https:// www.youtube.com/watch?v=MhVHE5V49oA. Accessed 13 August 2019.

Wandor, Michelene. 2008. The Author Is Not Dead, Merely Somewhere Else: Creative Writing After Theory. Basingstoke and New York: Palgrave Macmillan.

Westbrook, Steve. 2004. Just Do $\mathrm{It}^{\mathrm{TM}}$ : Creative Writing Exercises and the Ideology of American Handbooks. New Writing: the International Journal for the Practice and Theory of Creative Writing 1 (2): 141-148.

Whitehead, Alfred North. 1967. Adventures of Ideas. New York: Free Press. 1978. Process and Reality: An Essay in Cosmology, ed. David Ray Griffin and Donald W. Sherburne. New York: Free Press.

Open Access This chapter is licensed under the terms of the Creative Commons Attribution 4.0 International License (http://creativecommons.org/licenses/ by $/ 4.0 /$ ), which permits use, sharing, adaptation, distribution and reproduction in any medium or format, as long as you give appropriate credit to the original author(s) and the source, provide a link to the Creative Commons license and indicate if changes were made.

The images or other third party material in this chapter are included in the chapter's Creative Commons license, unless indicated otherwise in a credit line to the material. If material is not included in the chapter's Creative Commons license and your intended use is not permitted by statutory regulation or exceeds the permitted use, you will need to obtain permission directly from the copyright holder.

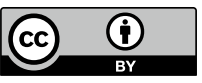

